\title{
VSC Control Strategy for Systems with high penetration of Power Electronic Converters
}

\author{
Marcial Gonzalez de Armas ${ }^{1}$, Jose Luis Rodriguez Amenedo ${ }^{1}$, Santiago Arnaltes Gomez ${ }^{1}$ and \\ Jaime Alonso-Martinez ${ }^{1}$
}

\author{
${ }^{1}$ Department of Electrical Engineering \\ E.P.S., Universidad Carlos III de Madrid \\ Campus of Leganes, 28911 Madrid (Spain)
}

\begin{abstract}
Phone/Fax number: +34 916 248851, e-mail: marcigon@pa.uc3m.es, amenedo@ing.uc3m.es, arnalte@ing.uc3m.es, jalonsom@ing.uc3m.es
\end{abstract}

\begin{abstract}
This paper presents a Voltage Source Converter (VSC) with an implemented Virtual Synchronous Machine (VSM) control strategy, which is able to work in both grid-tied and islanded mode, providing inertia to the grid and regulating the frequency and the voltage of the system. Those capabilities are necessary to make possible a high penetration of power electronic converters in the power grid. Converters work in parallel with the conventional generators while being able to deal with islanding or some other critical grid events. The proposed control strategy has been tested in a test bench with a synchronous generator (SG). When islanding the VSC, the converter demonstrates its grid forming capabilities controlling the frequency and voltage of the microgrid. The VSM control has proved its grid forming and grid supporting capabilities, without switching between control modes, making it ideal to react to different grid events and showing a soft transition between grid-tied and islanded operation modes.
\end{abstract}

Key words. VSC, VSM, Inertia Emulation, PMSG, Reactive Power Synchronization.

\section{Introduction}

Electronic converters are acquiring every day a more important role in the electrical grid. Being essential for the development of renewable energy sources, they are also becoming an important part of the microgrids [1]. In all cases, converters should be able to support the grid, maintaining the frequency and the voltage level in order to maximize the share of renewable energy sources (RES) in the grid.

In addition, for improving the reliability of the grid, electronic converters should also be able to work in both grid-tied and islanded mode, because different events in the grid may lead to a grid disconnection, leaving the converter in charge of a separated microgrid. That is very important for distributed generation (DG), which will need grid forming capabilities in the event of a fault in the grid [2].

Voltage Source Converters (VSC) appear as a great solution for improving the adaptability of the converters. Their grid forming capabilities combined with a good dynamic response make this kind of converters an optimal solution for the integration of RES in the system, the control of microgrids or even an HVDC transmission system [3]. To control the VSC, it is necessary to synchronize the frequency of the converter with the system. This is usually made using a Phase Locked Loop (PLL) [4], [5]. However, the use of PLLs may present instabilities and measurement errors, which is why many grid operators such as National Grid are recommending to use other alternatives [6].

Trying to emulate the synchronous generator's synchronizing torque, the idea of a Virtual Synchronous Machine has been proposed by many authors [7]-[9] VSMs have been proven as an effective method for both grid supporting and grid forming operations, facing many stability issues and providing virtual inertia to the power system [10]-[12]. Nowadays, this transition between grid forming and grid supporting control strategies is being addressed very often in the literature [13]-[15].

In this paper, a VSM control strategy for VSC using a reactive power synchronization loop is presented, which does not require the use of a PLL. The presented case studies which include a synchronous generator connected in parallel with the VSC will demonstrate the capability of the VSM control strategy to make a soft transition between grid supporting and grid forming operation mode.

Section 2 will introduce the proposed inner voltage and frequency control. The reactive power synchronization mechanism will be explained in Section 3. Section 4 will describe the proposed VSM control loops. The considered case studies and the simulation results will be presented and discussed in Section 5.

\section{VSC voltage and frequency control}

In order to control the voltage and frequency, the $\mathrm{dq}$ components of the current in a given reference frame, which flows through the capacitor of the LC filter at the output of the VSC (Fig. 1) will be controlled [4], [16]. 


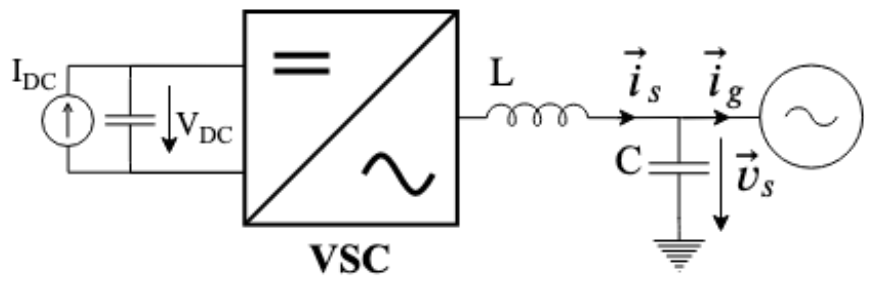

Fig. 1 AC capacitor voltage control through VSC output current.

According to Fig. 1, the following equations can be obtained for the $\mathrm{d}$ and $\mathrm{q}$ components of the current $i_{g}$ :

$$
\begin{aligned}
& i_{d s}-i_{g s}=C \frac{d v_{d s}}{d t}-\omega C v_{q s} \\
& i_{q s}-i_{g q}=C \frac{d v_{q s}}{d t}+\omega C v_{d s}
\end{aligned}
$$

From (1) and (2) it can be deducted that $v_{d s}$ can be controlled by $i_{d s}$ and $v_{q s}$ can be controlled by $i_{q s}$. When $v_{q s}=0$, the voltage frequency equals the reference frequency $\omega^{*}$. When $v_{q s}=0$ and $v_{d s}=v_{s}$ the following equations can be obtained:

$$
\begin{aligned}
& P_{s}-P_{g}=C v_{s} \frac{d v_{s}}{d t} \\
& Q_{g}=Q_{s}+\omega C v_{s}^{2}
\end{aligned}
$$

Equations (3) and (4) shows a relation between the active power flowing into the capacitor $\left(P_{s}-P_{g}\right)$ and the voltage $v_{s}$ and between the reactive power flowing into the capacitor $\left(Q_{g}-Q_{s}\right)$ and the frequency of the system $\omega$.

\section{Reactive Power Synchronization}

This method is based on obtaining a frequency deviation, $\Delta \omega$, proportional to the reactive power deviation. With the frequency deviation obtained, the reference angle $\theta$ is given by:

$$
\begin{gathered}
\Delta \omega=k_{Q}\left(Q_{s}-Q_{s}^{r e f}\right) \\
\theta=\theta_{0}+\int\left(\omega_{0}+\Delta \omega\right) d t
\end{gathered}
$$

Fig. 2 shows the reference angle $\theta$ calculation from $\Delta \omega$ using reactive power deviation with a droop constant $k_{Q}$, according to equations (5) and (6), which has been proven to be more stable than the active power synchronization [12], and it has better behaviour than the widely used PLL synchronization methods.

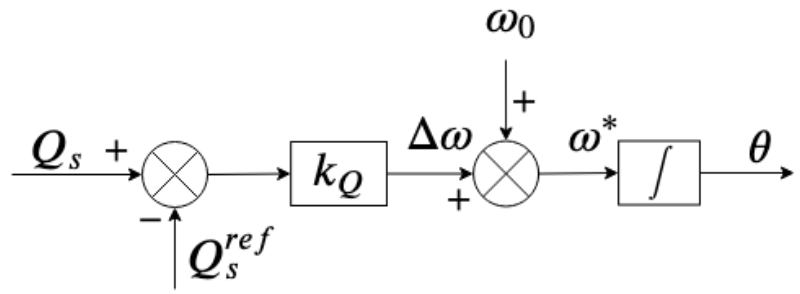

Fig. 2 Reactive power synchronization control loop.

\section{Virtual Synchronous Machine}

Using the reactive power synchronization method described in the last section, Fig. 3 and Fig. 4 show the proposed control loops for obtaining the reference current $i_{s}^{*} \mathrm{dq}$ components, $i_{d s}^{*}$ and $i_{q s}^{*}$. Standard current control loops will impose $i_{s}^{*}$ at the converter output, avoiding overcurrent with a fast dynamic response.

The current $i_{d s}^{*}$ is the result of three signals: one proportional to the frequency deviation $\Delta \omega$ with a droop constant $k_{\omega}$; the voltage at the capacitor $v_{d s}$ regulation loop; and $\mathrm{i}_{d \text { ref }}$ a preset output current for the stationary state, when $\Delta \omega=0$ and $v_{d s}$ is imposed by the grid. This makes the converter operate similar to a synchronous generator, regulating voltage and frequency values with a virtual inertia.

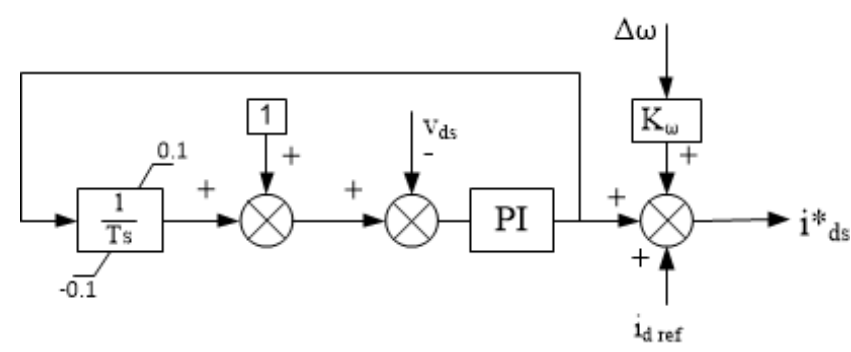

Fig. 3 VSM reference current $i_{d s}^{*}$ calculation.

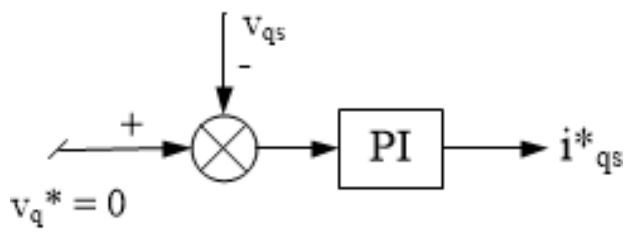

Fig. 4 VSM reference current $i_{q S}^{*}$ calculation.

The current $i_{q s}^{*}$ is set to orientate the voltage vector to the reference axis, given by the reactive power synchronisation loop, by making $v_{q}^{*}=0$.

VSM control strategy will be the same for both islanded and grid tied operation, controlling both frequency and voltage with its own inertia and better dynamic response than a SG.

\section{Simulations and Discussion}

In order to study the soft transition of the presented VSM control strategy between grid supporting and grid forming 
operation modes, two different simulation case studies are presented.

\section{A. Case Study I: VSM working as spinning reserve}

Fig. 5 shows a general scheme of the system under study, where a SG in parallel with a VSC is connected to a $220 \mathrm{kV}$ bus bar, where a passive, purely resistive load is connected.

The main parameters of the system under study are shown in Table I.
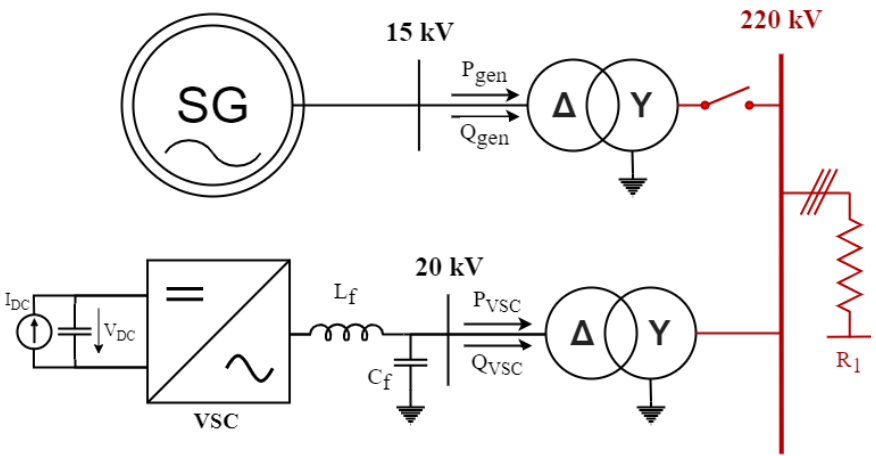

Fig. 5 Description of the system implemented in Case Study I

Table I - Study system's parameters

\begin{tabular}{|l|c|c|}
\hline \multicolumn{1}{|c|}{ Description } & Value & Units \\
\hline Base frequency & 50 & $\mathrm{~Hz}$ \\
\hline SG rated power & 600 & $\mathrm{MVA}$ \\
\hline SG voltage level & 15 & $\mathrm{kV}$ \\
\hline VSC rated power & 200 & $\mathrm{MVA}$ \\
\hline VSC voltage level & 20 & $\mathrm{kV}$ \\
\hline VSC output Reactance value $\left(L_{f}\right)$ & 0.955 & $\mathrm{mH}$ \\
\hline VSC output Capacitor value $\left(C_{f}\right)$ & 167 & $\mu \mathrm{F}$ \\
\hline Load voltage level & 220 & $\mathrm{kV}$ \\
\hline Load value $\left(R_{1}\right)$ & 322.7 & $\Omega$ \\
\hline Load nominal power & 150 & $\mathrm{MW}$ \\
\hline DC voltage level $\left(V_{D C}\right)$ & 40 & $\mathrm{kV}$ \\
\hline
\end{tabular}

For the system depicted in Fig. 5, starting from stationary state, the switch installed in the $220 \mathrm{kV}$ bus bar at the SG transformer's output will open the circuit at $T=10$ seconds, disconnecting the SG from the system and leaving the VSC in an islanded grid.

At this stationary state, the SG is fully supplying the load $\left(P_{G E N} \approx 150 \mathrm{MW}\right.$ ) while the VSC is working as spinning reserve $\left(P_{V S C} \approx 0 \mathrm{MW}\right)$, with VSM control mode implemented, so it can be presumed that right after the disconnection of the SG, the VSC will assume the load and the control of the system.

Fig. 6 shows results for the case study. The power output of the SG $\left(P_{G E N}\right)$ instantaneously drops to 0 at $T=10 \mathrm{~s}$. The VSC is left as the only generator in the system and starts to inject power to maintain the capacitor's voltage level and the frequency of the system at their nominal values.
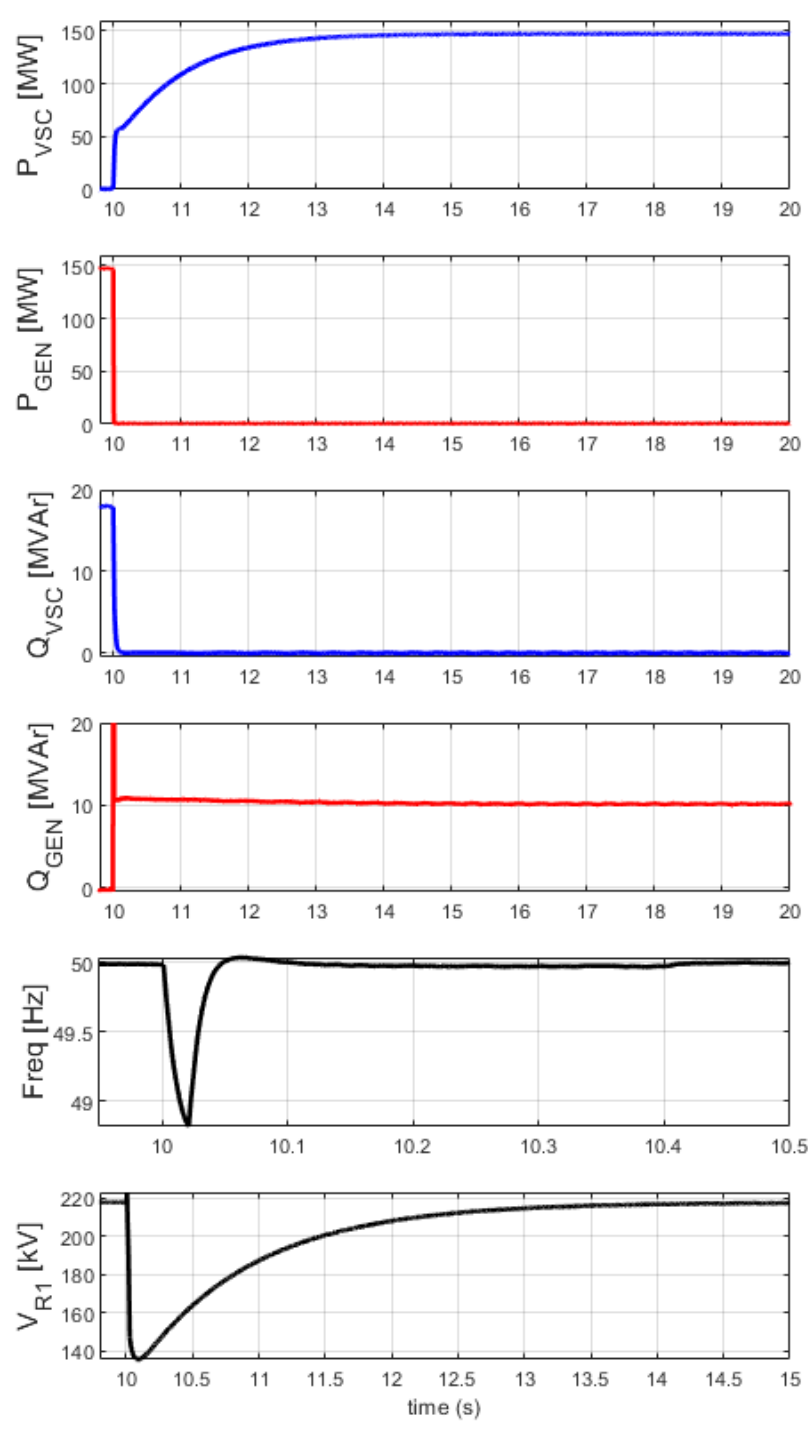

Fig. 6 Results for the Case Study I.

The active power output of the VSC $\left(P_{V S C}\right)$ does not instantaneously go to $150 \mathrm{MW}$ at $T=10 \mathrm{~s}$. The behaviour of $P_{V S C}$ on Fig. 6 is due to the voltage drop cause by the disconnection of the SG which is also depicted in the figure.

The reactive output power of the $\operatorname{VSC}\left(Q_{V S C}\right)$ goes to 0 once the converter is left in an islanded grid. The reactive power synchronization loop will instantaneously control the frequency imposing its own reference $\omega_{0}$ as it is shown in Fig. 2 and guaranteeing the reference $v_{q \text { ref }}^{*}=0$.

The stationary behaviour of the system is fully recovered at $T=14 \mathrm{~s}$. However, the frequency of the system is driven back to $50 \mathrm{~Hz}$ in less than $100 \mathrm{~ms}$ and the frequency at nadir is above $48.5 \mathrm{~Hz}$. 


\section{B. Case Study II: VSM feeding a local load}

For this case study, a change in the loads is introduced for the system shown in Fig. 5, as Fig. 7. In this simulation two passive, purely resistive loads are connected to the 220 $\mathrm{kV}$ bus bar.

The parameters of the system are the ones used for the previous case study (Table I), introducing a symmetrical local load $R_{2}$. Both loads are demanding $150 \mathrm{MW}$ each one $\left(R_{1}=R_{2}=322.7 \Omega\right)$.
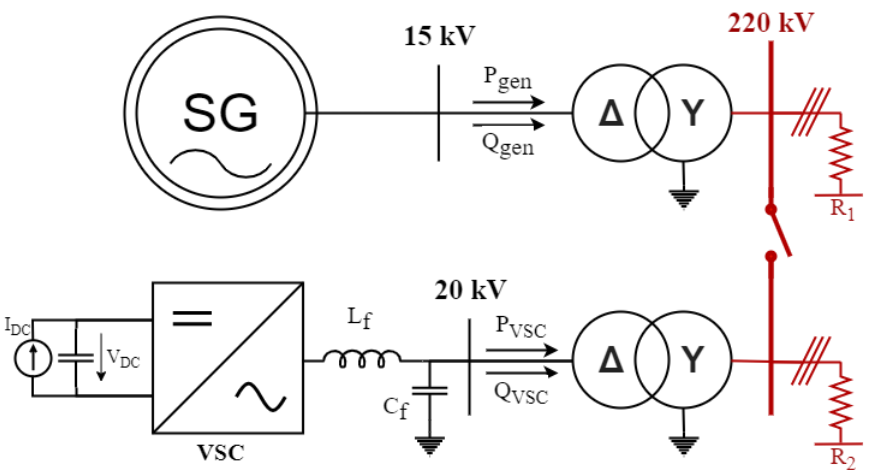

Fig. 7 Description of the system implemented in Case Study II

At the initial stationary state, the VSC is feeding partially its local load $\left(P_{V S C}=100\right)$ and the $S G$ is supplying the rest of the total load $\left(P_{G E N}=200\right)$. At $T=10$ seconds, the switch depicted on Fig. 7 will open the $220 \mathrm{kV}$ bus bar midpoint, so each generator will be left alone feeding a 150 MW load in an islanded system.

With the presented control strategy, the VSC will show its grid forming capabilities, adjusting its output power to fully feed the local load $R_{2}$.

The results of the simulation are shown in Fig. 8. The VSC shows the same behaviour as in the previous case study, its power output rise to $150 \mathrm{MW}$. Again, the behaviour of $P_{V S C}$ on Fig. 8 is due to the voltage drop at

$T=10$ seconds. The reactive power instantaneously reaches its stationary value in less than $100 \mathrm{~ms}$.

In this case, the system also reaches a stationary behaviour at $T=14$ seconds. The frequency of the system is still driven back to $50 \mathrm{~Hz}$ very quickly (less than $100 \mathrm{~ms}$ after the switch is open) and the frequency at nadir is above 49.3 $\mathrm{Hz}$, so the perturbation appears to be even lower in this case.

\section{Discussion of the results}

In both scenarios, one initially acting as a spinning reserve and the other one partially supplying a local load, the system shows a soft transition between grid supporting and grid forming mode, without changing its control strategy.
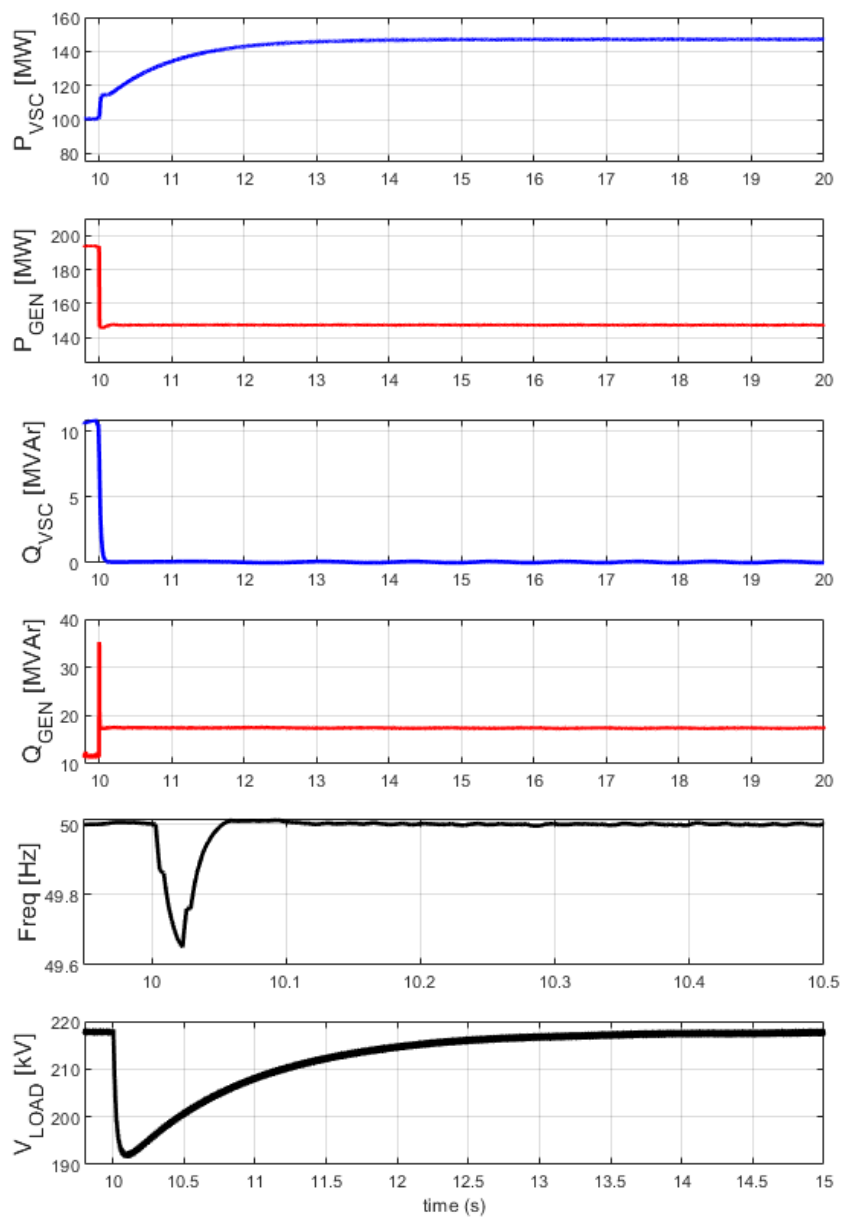

Fig. 8 Results for the Case Study II.

While the frequency is driven back to its nominal value in a short period of time, the voltage level drops significantly (to $0.65 \mathrm{pu}$ in the first case and $0.85 \mathrm{pu}$ in the second scenario), that is caused by a sudden active power demand. However, the VSC is able to recover the stationary state injecting active power and fully supplying the load.

The reactive power behaviour does not show any undesired transient behaviour, reaching its nominal value right after the grid event. Before the grid event, the VSC is giving some reactive power to the SG side. After the grid event the reactive power is fully controlled by the VSC and driven to its preset stationary value $\left(Q_{S}^{r e f}=0\right.$ for all case studies).

\section{Conclusions}

A VSM control strategy for VSC has been proposed and tested during different grid events, leaving the converter operating in islanded mode. The control strategy has demonstrated the VSM capability to operate in both gridtied and grid forming mode without switching between control strategies.

After a sudden disconnection of the SG, the converter can maintain the nominal frequency in less than $100 \mathrm{~ms}$, avoiding a black out in the system and acting as a spinning reserve with a virtual inertia. 
Despite the sudden voltage drop in the $220 \mathrm{kV}$ bus bar caused by the critical grid event, the VSC was able to restore the nominal voltage in less than 4 seconds in both cases, minimizing the voltage droop and supplying the load without a frequency deviation.

The converter does not change the VSM control mode, it just maintains the desired voltage and frequency providing inertia and the system reliability. After reaching the stationary state, the converter is able to control the system frequency and voltage demonstrating its grid forming capability.

\section{Acknowledgement}

This work has been supported by the Autonomous Community of Madrid under the PROMINT-CM project (P2018/EMT-4366).

\section{References}

[1] N. Sinenian and D. Shai, "Advances in Power Converters," in The Power Grid, Elsevier, 2017, pp. 5792.

[2] A. M. Egwebe, M. Fazeli, P. Igic, and P. M. Holland, "Implementation and Stability Study of Dynamic Droop in Islanded Microgrids," IEEE Trans. Energy Convers., vol. 31, no. 3, pp. 821-832, 2016.

[3] B. Muftau, M. Fazeli, and A. M. Egwebe, "New control paradigm for both islanded and grid-connected operation of PMSG-based wind turbine," J. Eng., vol. 2019, no. 18, pp. 5142-5146, 2019.

[4] A. Yazdani and R. Iravani, Voltage-Sourced Converters in Power Systems, vol. 34. Hoboken, NJ, USA: John Wiley \& Sons, Inc., 2010.

[5] J. Svensson, "Synchronisation methods for gridconnected voltage source converters," IEE Proc. - Gener. Transm. Distrib., vol. 148, no. 3, p. 229, 2001.

[6] National Grid, "Perform of Phase-Locked Loop Based Converters," System Operability Framework, 2017.

[7] H. P. Beck and R. Hesse, "Virtual synchronous machine," 2007 9th Int. Conf. Electr. Power Qual. Util. EPQU, 2007.

[8] S. D'Arco, J. A. Suul, and O. B. Fosso, "A Virtual Synchronous Machine implementation for distributed control of power converters in SmartGrids," Electr. Power Syst. Res., vol. 122, pp. 180-197, 2015.

[9] Y. Chen, R. Hesse, D. Turschner, and H.-P. Beck, "Comparison of methods for implementing virtual synchronous machine on inverters," Renew. Energy Power Qual. J., vol. 1, no. 10, pp. 734-739, 2012.

[10] H. Hanaoka and M. Nagai, "Development of a novel parallel redundant UPS," 25th Int. Telecommun. Energy Conf. 2003. INTELEC '03., pp. 493-498, 2003.

[11] J. M. Guerrero, N. Berbel, J. Matas, L. G. De Vicuña, and J. Miret, "Decentralized control for parallel operation of distributed generation inverters using resistive output impedance," IECON Proc. (Industrial Electron. Conf., vol. 54, no. 2, pp. 5149-5154, 2006.

[12] A. Peña Asensio, S. Arnaltes, J. L. Rodriguez-Amenedo, and M. A. Cardiel-Alvarez, "Reactive Power Synchronization Method for Voltage Sourced Converters," IEEE Trans. Sustain. Energy, vol. 10, no. 3, pp. 1-1, 2019.
[13] V. L. Srinivas, B. Singh, and S. Mishra, "Self Synchronizing VSM with Seamless Operation during Unintentional Islanding Events," IEEE Trans. Ind. Informatics, vol. PP, no. c, p. 1, 2019.

[14] S. D'Arco and J. A. Suul, "A synchronization controller for grid reconnection of islanded virtual synchronous machines," 2015 IEEE 6th Int. Symp. Power Electron. Distrib. Gener. Syst. PEDG 2015, pp. 1-8, 2015.

[15] B. Muftau, M. Fazeli, and A. M. Egwebe, "Stability analysis of a PMSG based Virtual Synchronous Machine," IEEE PES Trans. Energy Convers., vol. 180, no. October 2019, p. 106170, 2019.

[16] A. Pena Asensio, S. Arnaltes Gomez, J. L. RodriguezAmenedo, M. García Plaza, J. E. Garcia Carrasco, and J. M. Alonso-Martinez, "A voltage and frequency control strategy for stand-alone full converter wind energy conversion systems," Energies, vol. 11, no. 3, 2018. 